University of Nebraska - Lincoln

DigitalCommons@University of Nebraska - Lincoln

Publications from USDA-ARS / UNL Faculty

U.S. Department of Agriculture: Agricultural

Research Service, Lincoln, Nebraska

2012

\title{
Molecular crosstalk between a chemical and a biological stressor and consequences on disease manifestation in rainbow trout
}

\author{
Richard Burki \\ University of Berne \\ Aleksei Krasnov \\ NOFIMA Marin \\ Kathrin Bettge \\ University of Berne \\ Caird E. Rexroad III \\ USDA-ARS
}

Sergey Afanasyev

Sechenov Institute of Evolutionary Physiology and Biochemistry

See next page for additional authors

Follow this and additional works at: https://digitalcommons.unl.edu/usdaarsfacpub

Part of the Agricultural Science Commons

Burki, Richard; Krasnov, Aleksei; Bettge, Kathrin; Rexroad, Caird E. III; Afanasyev, Sergey; Antikainen, Miia; Burkhardt-Holm, Patricia; Wahli, Thomas; and Segner, Helmut, "Molecular crosstalk between a chemical and a biological stressor and consequences on disease manifestation in rainbow trout" (2012).

Publications from USDA-ARS / UNL Faculty. 838.

https://digitalcommons.unl.edu/usdaarsfacpub/838

This Article is brought to you for free and open access by the U.S. Department of Agriculture: Agricultural Research Service, Lincoln, Nebraska at DigitalCommons@University of Nebraska - Lincoln. It has been accepted for inclusion in Publications from USDA-ARS / UNL Faculty by an authorized administrator of DigitalCommons@University of Nebraska - Lincoln. 


\section{Authors}

Richard Burki, Aleksei Krasnov, Kathrin Bettge, Caird E. Rexroad III, Sergey Afanasyev, Miia Antikainen, Patricia Burkhardt-Holm, Thomas Wahli, and Helmut Segner 


\title{
Molecular crosstalk between a chemical and a biological stressor and consequences on disease manifestation in rainbow trout
}

\author{
Richard Burki ${ }^{a}$, Aleksei Krasnov ${ }^{b}$, Kathrin Bettge a , Caird E. Rexroad III ${ }^{c}$, Sergey Afanasyev ${ }^{d}$, \\ Miia Antikainen ${ }^{\mathrm{e}}$, Patricia Burkhardt-Holm ${ }^{\mathrm{f}}$, Thomas Wahli ${ }^{\mathrm{a}}$, Helmut Segner ${ }^{\mathrm{a}, *}$ \\ a Centre for Fish and Wildlife Health, University of Bern, Länggassstrasse 122, CH-3001 Bern, Switzerland \\ b NOFIMA Marin, Postboks. 5010, 1432Ås, Norway \\ ' National Center for Cool and Cold Water Aquaculture, USDA-ARS, 11876 Leetown Road, Kearneysville, WV 25430, USA \\ d Sechenov Institute of Evolutionary Physiology and Biochemistry, M. Toreza av. 44, Peterburg 194223, Russia \\ e Institute of Applied Biotechnology, University of Kuopio, Finland \\ ${ }^{\mathrm{f}}$ Man-Society-Environment, University of Basel, Vesalgasse 1, CH-4051 Basel, Switzerland
}

\section{A R T I C L E I N F O}

\section{Article history:}

Received 30 November 2011

Received in revised form 18 February 2012

Accepted 21 February 2012

\section{Keywords:}

Pathogen

Proliferative kidney disease

Estrogen

Endocrine disruption

Multiple stressors

Rainbow trout

\begin{abstract}
A B S T R A C T
The aim of the present study was to examine the molecular and organism reaction of rainbow trout, Oncorhynchus mykiss, to the combined impact of two environmental stressors. The two stressors were the myxozoan parasite, Tetracapsuloides bryosalmonae, which is the etiological agent of proliferative kidney disease (PKD) and a natural stressor to salmonid populations, and $17 \beta$-estradiol (E2) as prototype of estrogen-active chemical stressors in the aquatic environment. Both stressors, the parasite and estrogenic contaminants, co-exist in Swiss rivers and are discussed as factors contributing to the decline of Swiss brown trout populations over the last decades. Using a microarray approach contrasting parasite-infected and non-infected rainbow trout at low or high estrogen levels, it was observed that molecular response patterns under joint exposure differed from those to the single stressors. More specifically, three major response patterns were present: (i) expression responses of gene transcripts to one stressor are weakened by the presence of the second stressor; (ii) expression responses of gene transcripts to one stressor are enhanced by the presence of the second stressor; (iii) expression responses of gene transcripts at joint treatment are dominated by one of the two stressors. Organism-level responses to concurrent E2 and parasite treatment - assessed through measuring parasite loads in the fish host and cumulative mortalities of trout - were dominated by the pathogen, with no modulating influence of E2. The findings reveal function- and level-specific responses of rainbow trout to stressor combinations, which are only partly predictable from the response to the single stressors.
\end{abstract}

(C) 2012 Elsevier B.V. All rights reserved.

\section{Introduction}

In nature, organisms are usually exposed to multiple stressors including biological, chemical and physical entities. In environmental sciences, much emphasis is given on the impact of single stressors, disregarding possible interactive effects arising from aggregate exposure to multiple stressors (Folt et al., 1999; Heugens et al., 2001; Crain et al., 2008; Sheras and Ross, 2010). For instance, natural stress situations such as poor food supply or infection with pathogens can change the response of organisms to toxic chemicals (Segner, 1987; Braunbeck and Segner, 1992; Jokela et al., 2005; Coors and De Meester, 2008). Similarly, exposure to toxic chemicals

\footnotetext{
* Corresponding author. Tel.: +410 03163124 41; fax: +410316312611.

E-mail addresses: helmut.segner@vetsuisse.unibe.ch, helmut.segner@itpa.unibe.ch (H. Segner).
}

can influence the ability of organisms to cope with natural stressors (Arkoosh et al., 1998; Kiesecker, 2002; Springman et al., 2005; Morley, 2010; Song et al., 2011). Several examples from field studies point to the importance of combined actions of anthropogenic and natural stressors on manifestation and dynamics of environmental disease (Kiesecker et al., 2001; Landis et al., 2004; Rohr et al., 2008), but currently we lack concepts for the risk assessment of multiple stressors (Callahan and Sexton, 2007; Altenburger and Greco, 2009). There is a strong need to better understand cumulative and interactive effects of chemical, biological and physical stressors, of strategies by which organisms deal with the demands placed on them by combined stressor exposure, how they prioritize stressors, and how their vulnerability to one stressor may be changed by exposure to a second stressor (Segner, 2007, 2011a; Couillard et al., 2008a,b; Sheras and Ross, 2010).

A pronounced decline of brown trout (Salmo trutta) has taken place in Switzerland during the last decades, and available evidence 
suggests that this is not caused by a single factor but rather by multiple factors (Burkhardt-Holm et al., 2005). One stressor that is suspected to play a key role in the brown trout decline is the proliferative kidney disease (PKD) which is caused by the myxozoan parasite Tetracapsuloides bryosalmonae. The disease is widespread in brown trout populations of Swiss rivers (Wahli et al., 2007) and can lead to high mortalities in infected populations, particularly in the young-of-the year life stage. PKD-induced mortalities are temperature-dependent, increasing strongly if summer water temperatures are reaching levels of approximately $15^{\circ} \mathrm{C}$ and higher (Bettge et al., 2009a,b). Such water temperatures occur mainly in rivers at low altitudes $(<600-800 \mathrm{~m}$ above sea-level), which are present in the Swiss midland region (Wahli et al., 2008). However, the midland region is also strongly urbanized and industrialized, and therefore many midland rivers are impacted by chemical pollution (Burkhardt-Holm et al., 2005; Goetz et al., 2010). This situation leads to the question if the adverse impact of PKD on brown trout populations in Swiss midland rivers could be potentiated by simultaneous exposure of trout to chemical contaminants.

The aim of the present study is to examine in a laboratory environment the combined impact of $T$. bryosalmonae-infection and contaminant exposure on fish. The contaminant group selected for this purpose is estrogen-active compounds. These substances are present in Swiss midland rivers (Vermeirssen et al., 2005; Burki et al., 2006), and, in addition to their well-known effects on the reproductive physiology (Segner, 2011b), they can modulate immunocompetence of fishes and their susceptibility towards pathogens (Thilagam et al., 2009; Cabas et al., 2011; CasanovaNakayama et al., 2011; Milla et al., 2011; Wenger et al., 2011). Experimentally, young-of-the-year rainbow trout, were (i) infected with the parasite, $T$. bryosalmone, (ii) exposed to the prototype estrogenic substance $17 \beta$-estradiol (E2), or (iii) treated with a combination of the parasite and E2. Treatment effects were compared at the levels of transcript expression of genes, intensity of parasite infection of the fish, and fish survival. Hepatic expression profiles of gene transcripts were measured using a trout cDNA microarray platform which has been extensively validated for assessing salmonid responses to stressors (Krasnov et al., 2005, 2007; Koskinen et al., 2004; MacKenzie et al., 2006). Liver was selected as target organ as the liver of fish integrates responses to diverse types of environmental stressors and as it plays an important role in immunity (Rice, 2001).

\section{Materials and methods}

\subsection{Exposure of rainbow trout to estrogen and T. bryosalmonae} (PKD)

Two batches of juvenile (young-of-the-year) rainbow trout (age $0+$, weight $1.5-4 \mathrm{~g}$ ) of the same genetic origin were obtained from a fish farm. The two batches did not differ in terms of body weight and body length, but one batch was infected with T. bryosalmonae, while the other batch consisted of healthy, non-infected fishes. Representative samples of both batches were analysed for T. bryosalmonae infection status by means of PCR. The results showed $100 \%$ prevalence in the batch with infected fishes, while in the control batch, no single fish was positive for the parasite. Overt disease signs such as swollen excretory kidneys or anemia were not present in the infected fishes at the beginning of the experiment. The fishes were kept in $100 \mathrm{~L}$ flow-through aquaria, with PKD-positive and -negative rainbow trout in the same aquaria since the disease is not transmitted from fish to fish (D'Silva et al., 1984). To distinguish non-infected from infected fishes, the latter were marked by a cut of the adipose fin. After an acclimation period of 1 week at a water temperature of $14^{\circ} \mathrm{C}$, an initial sampling for biometric, microarray and PCR analyses was done. Afterwards, water temperature was slowly elevated to $18^{\circ} \mathrm{C}$ as this temperature promotes the clinical outbreak of PKD (Bettge et al., 2009a,b). The fish were fed with (i) feed without hormone addition, (ii) feed supplemented with a low amount of E2 ( $0.5 \mathrm{mg}$ E2 $/ \mathrm{kg}$ food) and (iii) feed supplemented with a high amount of E2 (20 mg E2/kg food). E2 (Sigma, Buchs, Switzerland) was incorporated into pelleted trout dry food (Hokovit, Bützberg, Switzerland) using the alcohol evaporation method (Guerrero, 1975). Actual E2 concentrations in the diet were confirmed by HPLC analysis, and the efficiency of the dietary E2 treatment to induce an estrogenic response was assessed by measuring hepatic mRNA expression of the estrogenic biomarker, vitellogenin (VTG).

The experimental treatments were as follows:

(1) temperature control $\left(18^{\circ} \mathrm{C}\right.$, no PKD, no E2) (T); this group was included in order to control for the effect of the temperature increase from 14 to $18{ }^{\circ} \mathrm{C}$ on the hepatic transcriptome

(2) low amount of E2 (LE), no PKD

(3) high amount of E2 (HE), no PKD

(4) PKD infection (I), no E2

(5) PKD infection plus low amount of E2 (ILE)

(6) PKD infection plus high amount of E2 (IHE).

Fish were kept under the experimental conditions for 25 days. All treatments were run in duplicate ( $n=80$ per replicate; $n=160$ per treatment). Mortalities were recorded daily and used for calculation of cumulative mortalities. Since the main interest in this study was to assess stress responses of trout transcriptome under combined PKD and E2 impact, we decided to perform no sampling shortly before the onset of disease-induced mortality, but only during the late disease stage, after the level of maximum mortality had been reached, which was the case at day 20. Afterwards, mortality rates decreased drastically and sampling for expression analysis of gene transcripts was then done at day 25. In this way, we examined fish that are likely to survive the treatments and largely excluded moribund fish which could confound the transcript expression results. For sampling, fish were anaesthetized with buffered 3-aminobenzoic acid ethyl ester methanesulphonate (Argent Chemical Laboratories, Redmont, CA, USA). Livers and kidneys were removed and stored either in RNAlater (Ambion, Austin, USA) (livers) for later expression analysis or in liquid nitrogen (kidneys) for later analysis of parasite DNA.

All animals used in this study have been treated humanely according to the Swiss regulations for animal Welfare with regard for alleviation of suffering.

\section{Microarray analysis}

We used high density salmonid fish microarray SFA3, an extended version of SFA2, which was described in detail elsewhere (Gene Expression Omnibus GPL1212; 34). This platform includes 1766 genes printed in 6 replicates each. In comparison with SFA2 it is substantially enriched in genes implicated in responses to pathogens and toxicity. The genes were annotated by the functional classes of Gene Ontology, GO (Ashburner et al., 2005).

Total RNA was extracted from the rainbow trout livers with Trizol (Invitrogen, Paisley, UK) and four individuals were pooled in each sample. Labeling and hybridization was performed as previously described in detail (Krasnov et al., 2007). The microarray hybridizations followed a common reference design with dye swap. The start sample (water temperature $14^{\circ} \mathrm{C}$, no PKD, no estrogen) was used as a control for all treatment groups ("common negative control"). Each pooled sample was hybridized to two microarrays. For the first slide, test and control cDNA were labeled with Cy5 
and Cy3, respectively, and for the second array, dye assignments were reversed. Since this experiment was performed with six different treatment groups (T, LE, HE, I, ILE and IHE), a total of twelve microarrays were used. Scanning was performed with ScanArray 5000. The quantification of the spots was done with TIGR Spotfinder (Institute of Genomic Research, MD, USA). The measurements were filtered by criterion $\left(I-S_{I}\right)>\left(B+S_{B}\right)$, where $I$ and $B$ are the mean signal and background intensities and $S_{I}, S_{B}$ are the standard deviations. After subtraction of mean background, Lowess normalization was performed separately with each slide. Using the dye swap design of hybridization, each gene was analyzed in 12 spot replicates. Data for two slides were consolidated and technical accuracy of differential transcript expression was assessed by the difference of $\log _{2}$ (Expression ratios) at the reverse labeling (Student's $t$-test, $p<0.01$ ).

The statistical analyses were conducted with 388 genes that showed differential transcript expression in at least two treatment groups. Hierarchical clustering of $\log _{2}$ (Expression Ratios) values by Euclidian distances with Ward's method was used for classification of samples and preliminary search for the groups of genes with similar transcript expression profiles. To define more exactly composition of the gene groups, Pearson correlation to the mean expression profile was determined for each member of cluster and genes with $r<0.74$ were discarded. The resulting groups are referred to as transcription modules (TM). Genes were assigned to the TMs exclusively by their expression profiles. A complementary approach was applied to include the functional annotations into statistical analyses. Genes were grouped by the GO categories and the mean $\log _{2}$ (Expression Ratios) were calculated. The effects of treatments were analyzed with multiple regression. For multiple linear regression analyses we assumed $\log _{2}$ (Expression Ratio) $=b_{1} I+b_{2} L_{E}+I n$, where $I$ and $L_{E}$ denote respectively the levels of infection and E2. The effects of treatments were assessed by significance of $b_{i}$, i.e. beta weights (standardized coefficients of multiple regression), while significant deviation of intercept (In) from zero indicated to possibility of joint effects. Complete expression data of gene transcripts and full composition of TMs are available in the on-line supplemental material.

\subsection{Real-time PCR for determination of intensity of infection by $T$. bryosalmonae}

Real-time PCR was used to quantify $T$. bryosalmonae DNA in trout kidneys. The method was performed according to the protocol of Bettge et al. (2009b), which is routinely used in the Berne laboratory.

\section{Results}

\subsection{Cumulative mortality}

Cumulative mortality was measured over the experimental period of 25 days. In the control group, i.e. non-infected and non E2exposed fishes kept at $18^{\circ} \mathrm{C}(\mathrm{T})$, mortality during the 25-day-period was negligible (only 1 fish died out of 160 ). Very low cumulative mortalities $(2.5 \%)$ were observed also in the two non-infected estradiol groups (LE, HE) (Fig. 1). In contrast, very high cumulative mortalities of almost $90 \%$ were recorded in T. bryosalmonaeinfected group. Additional exposure of $T$. bryosalmonae-infected fish to low (ILE) or high (IHE) levels of E2 did not significantly change cumulative mortalities compared to the "infection only" group, neither the absolute level of mortality nor the rate of mortality increase (Fig. 1). In order to evaluate if the dietary E2 was indeed accumulated and effective in the exposed fishes, we measured hepatic expression levels of vitellogenin (VTG) mRNA. Both

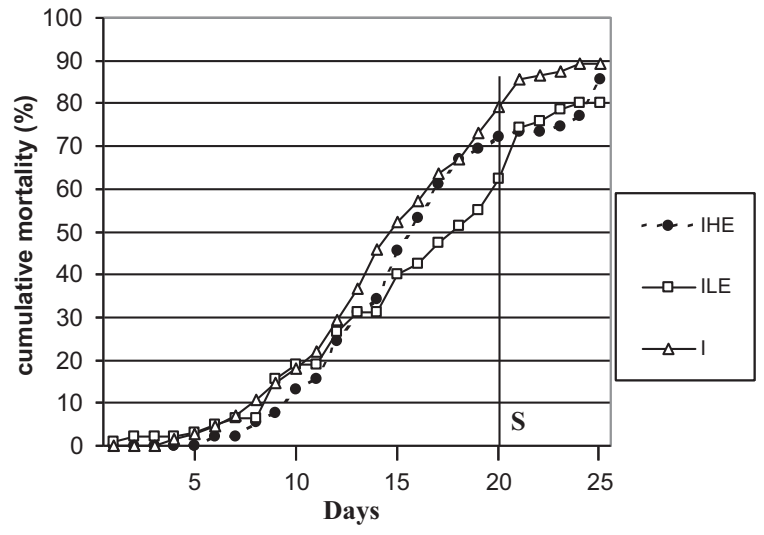

Fig. 1. Cumulative mortalities of the experimental groups: T. bryosalmonae infection (I), Tetracapsuloides bryosalmonae infection plus exposure to the low dose of E2 (ILE), or T. bryosalmonae infection plus exposure to the high dose of E2 (IHE). The line marked with $S$ represents the time point (day 20) when rainbow trout were sampled for microarray analysis and determination of parasite density.

in the non-infected and in the infected groups, E2 feeding resulted in a significant and dose-dependent elevation (data not shown).

\subsection{Prevalence and intensity of parasite infection}

The prevalence of infection was $100 \%$ in all groups with $T$. bryosalmonae infection (I, ILE, IHE), regardless whether the fishes were treated with E2 or not. Also parasite loads, estimated by measuring concentrations of parasite DNA in the infected kidneys, did not show significant differences between the infected group (I) and groups exposed to both the parasite and E2 (ILE, IHE) (Fig. 2). The same individuals used for determining parasite loads were also used for the microarray analyses (see below).

\subsection{Microarray analysis}

The transcriptional profile of rainbow trout liver in response to the presence of the two stressors, E2 and PKD, alone or in combination was investigated using a trout cDNA microarray. Hierarchical clustering of the transcript expression profiles of hepatic genes confirmed compliance between the treatments and transcriptomic responses. Main findings of the cluster analysis (Fig. 3) were that (a) the low E2 treatment (LE) was not clearly different from that of the $18^{\circ} \mathrm{C}$ control group (T) whereas the high level E2 treatment

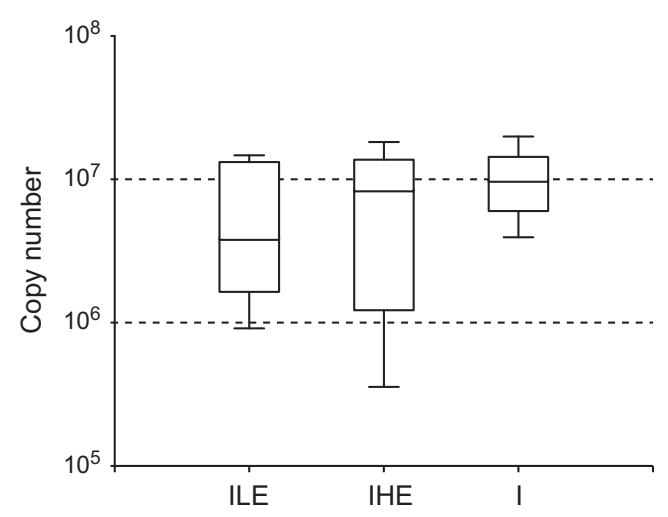

Fig. 2. Copy numbers of the $18 \mathrm{~s}$ rDNA gene of the parasite Tetracapsuloides bryosalmonae in excretory kidneys of infected rainbow trout (I), infected rainbow trout additionally treated with the low dose of E2 (ILE), or infected rainbow trout additionally treated with the high dose of E2 (IHE). The 18S rDNA copy numbers were determined by means of real time PCR. The results are presented as box plots indicating median, 75 th and 95 th percentiles. $N=10$ per treatment. 


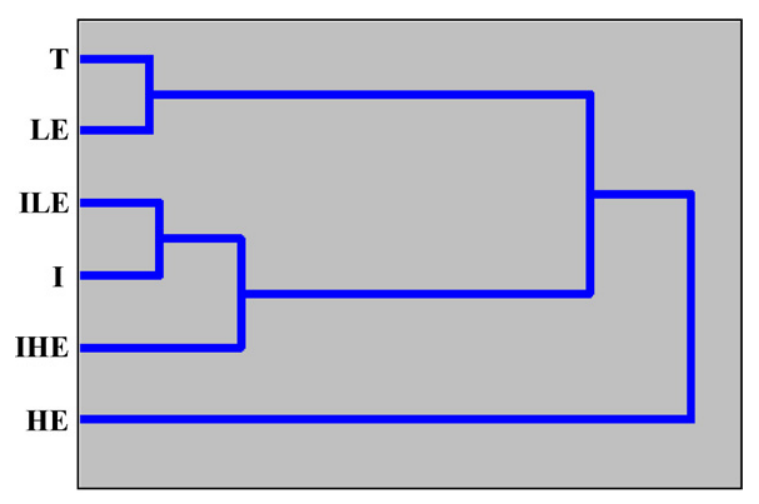

Fig. 3. Responses of the transcriptional expression of hepatic genes in rainbow trout to control conditions at $18^{\circ} \mathrm{C}(\mathrm{T})$, feeding with low (LE) and high (HE) levels of E2, T. bryosalmonae infection (I) or combinations of these treatments (ILE, IHE) (all at $18^{\circ} \mathrm{C}$ ). The $\log$ (expression ratios) values of 388 transcriptionally differentially expressed genes were clustered by Euclidian distances using Ward's method. For details see Material and Methods.

(HE) yielded a distinct expression signature that differed from $\mathrm{T}$ and LE, and (b) all T. bryosalmonae-infected groups separated from the non-infected groups, with I and ILE being very close to each other, and IHE being more distant. These findings point to a prevailing effect of infection over estrogen on transcript expression of rainbow trout hepatic genes.

To evaluate the effects of PKD and E2 and their interactions, multiple regression was applied to genes grouped according to either similarity of transcript expression profiles (transcription modules, TMs) or by Gene Ontology (GO) classes. Use of TMs instead of individual genes smoothes random fluctuations in expression of gene transcripts thereby increasing accuracy and robustness of statistical analyses. We successfully used this approach previously to dissect the effects of aquatic contaminants applied singly or in combinations (Krasnov et al., 2007). Though genes were selected exclusively by correlation of transcript expression changes regardless of their functional roles, the identified TMs included functionally related genes indicating that they possess biological relevance. Fig. 4 presents selected genes from the four identified TMs. GO categories with significant responses to the treatments are presented in Table 1 . The two independent approaches produced concordant results.

TM1 is characterized by stimulation by E2, particularly by the high levels of E2 (HE) (Fig. 4A). Infection significantly reduces the stimulatory effect of the hormone. Being heterogeneous by composition, TM1 nonetheless includes several groups of functionally

Table 1

Examples of gene ontology GO categories with responses to PKD and/or E2. The table reports the beta weights. Significant effects and interactions $(p<0.05)$ are indicated.

\begin{tabular}{|c|c|c|c|}
\hline GO functional category & $\begin{array}{l}\text { Number of } \\
\text { genes }\end{array}$ & $\begin{array}{l}\text { Beta weight } \\
\text { estrogen }\end{array}$ & $\begin{array}{l}\text { Beta weight } \\
\text { PKD }\end{array}$ \\
\hline Immune response $e^{a, b, c}$ & 93 & -0.138 & 0.194 \\
\hline $\begin{array}{l}\text { Humoral immune } \\
\text { response }^{\mathrm{a}, \mathrm{b}}\end{array}$ & 32 & -0.149 & 0.307 \\
\hline Complement activation ${ }^{\mathrm{b}}$ & 20 & -0.136 & 0.379 \\
\hline Chemokine activity & 5 & -0.163 & 0.504 \\
\hline Cell-cell signalingb & 8 & -0.189 & 0.401 \\
\hline $\begin{array}{l}\text { Primary active transporter } \\
\text { activity }^{\mathrm{a}}\end{array}$ & 16 & 0.330 & -0.156 \\
\hline ATP biosynthesis ${ }^{\mathrm{a}}$ & 4 & 0.680 & -0.114 \\
\hline Protein biosynthesis ${ }^{\mathrm{a}, \mathrm{b}}$ & 63 & 0.292 & -0.597 \\
\hline Superoxide metabolism ${ }^{\mathrm{a}, \mathrm{b}}$ & 3 & 0.596 & -0.735 \\
\hline Hemoglobin complex ${ }^{b}$ & 7 & -0.186 & -0.735 \\
\hline
\end{tabular}

a Significant response to estrogen.

b Significant response to PKD.

c Significant interaction of treatments. related genes. A large fraction (23 of 68 genes) is represented by genes encoding proteins involved in ATP synthesis (e.g., ATP synthase) and protein biosynthesis (e.g., 13 ribosomal proteins). Analyses by GO classes were in line with this finding, as hormonal treatment markedly stimulated the GO categories "ATP biosynthesis" and "protein biosynthesis" (Table 1). The observed stimulation of superoxide dismutase and peroxiredoxin transcripts (Fig. 4A) and transcripts associated with superoxide metabolism (Table 1) might be related to an estrogen-induced production of reactive oxygen species, as has been demonstrated in a number of studies (e.g., Felty, 2006). Estrogens are known to affect the coagulation cascade at the transcriptional level, with tissue factor pathway inhibitor being one of the targets (Jayachandran et al., 2005); this gene is also represented in TM1. The up-regulation of cyclin A2 transcript, polyposis locus protein transcript and transcripts of several genes involved in modification of chromosomes (e.g. transcripts of histone 3A-ATP synthase and histone deacetylase 9 genes) are indicative of the stimulatory influence of estradiol on cell proliferation (Sutherland et al., 1998). Further, we observed transcriptional up-regulation of cathepsin D gene, which is responsible for the specific proteolysis of the major egg yolk protein vitellogenin (Nakamura et al., 1996). It is noteworthy that a group of genes involved in lipid metabolism (genes encoding delta6 fatty acid desaturase, fatty acid-binding protein, high density lipoprotein-binding protein, sulfotransferase) were also significantly transcriptionally responsive to estrogen treatment. TM1 also included several immune system-related genes, e.g., those encoding leukocyte antigen CD37 and eosinophil chemotactic cytokine.

TM2 (Fig. 4B) includes genes that are transcriptionally downregulated with both experimental factors, though the effect of the parasite is markedly greater than that of E2 (the beta weights are -0.64 and -0.31 , respectively). An especially strong inhibitory response was seen in the hemoglobin complex (Table 1), a finding that is in concordance with the fact that anemia is a major clinical sign associated with the T. bryosalmonae-induced disease, PKD (Hedrick et al., 1993).

TM3 and TM4 are enriched in genes implicated in immune responses. TM3 (Fig. 4C) includes mainly genes involved in the innate immune response with predominance of plasma proteins (components of the complement system including properdin, acute phase protein and ceruloplasmin). TM4 (Fig. 4D) contains genes involved in communication between immune cells, i.e. those encoding cytokines and chemokines (CC chemokine SCYA110-1), their receptors ( $\mathrm{C} 3 \mathrm{a}$ chemotactic receptor) and downstream regulated genes (Ig kappa chain V-I region). Both TMs are significantly down-regulated by E2 (beta weights -0.199 and -0.741 ), pointing to a potential immunosuppressive action of E2 in rainbow trout. The response to $T$. bryosalmonae, however, differed between TM3 and TM4. TM3 showed a strong induction of transcript expression in response to T. bryosalmonae infection (beta weight 0.63 ) and this induction completely overrules the down-regulating effect of the high E2 (HE) treatment (Fig. 4C). In TM4 (Fig. 4D), in contrast to TM3, parasite-related induction of transcript expression (I) was modulated by the presence of low or high E2 concentrations (ILE, IHE). Analysis of transcriptionally differentially expressed genes grouped by GO classes are in line with the above findings since the predicted humoral immune response and complement activation showed opposite responses to PKD and E2 with no significant interactions between these stressors (Table 1).

Non-immune genes in TM3 which were transcriptionally stimulated by parasite infection and down-regulated by E2 included metallothioneins and cell cycle regulators. Transcriptional upregulation of metallothionein genes may indicate changes in sequestration of zinc, which is characteristic for various acute conditions. However, transcriptional metallothionein gene upregulation may also be indicative for oxidative stress (e.g., Kling 

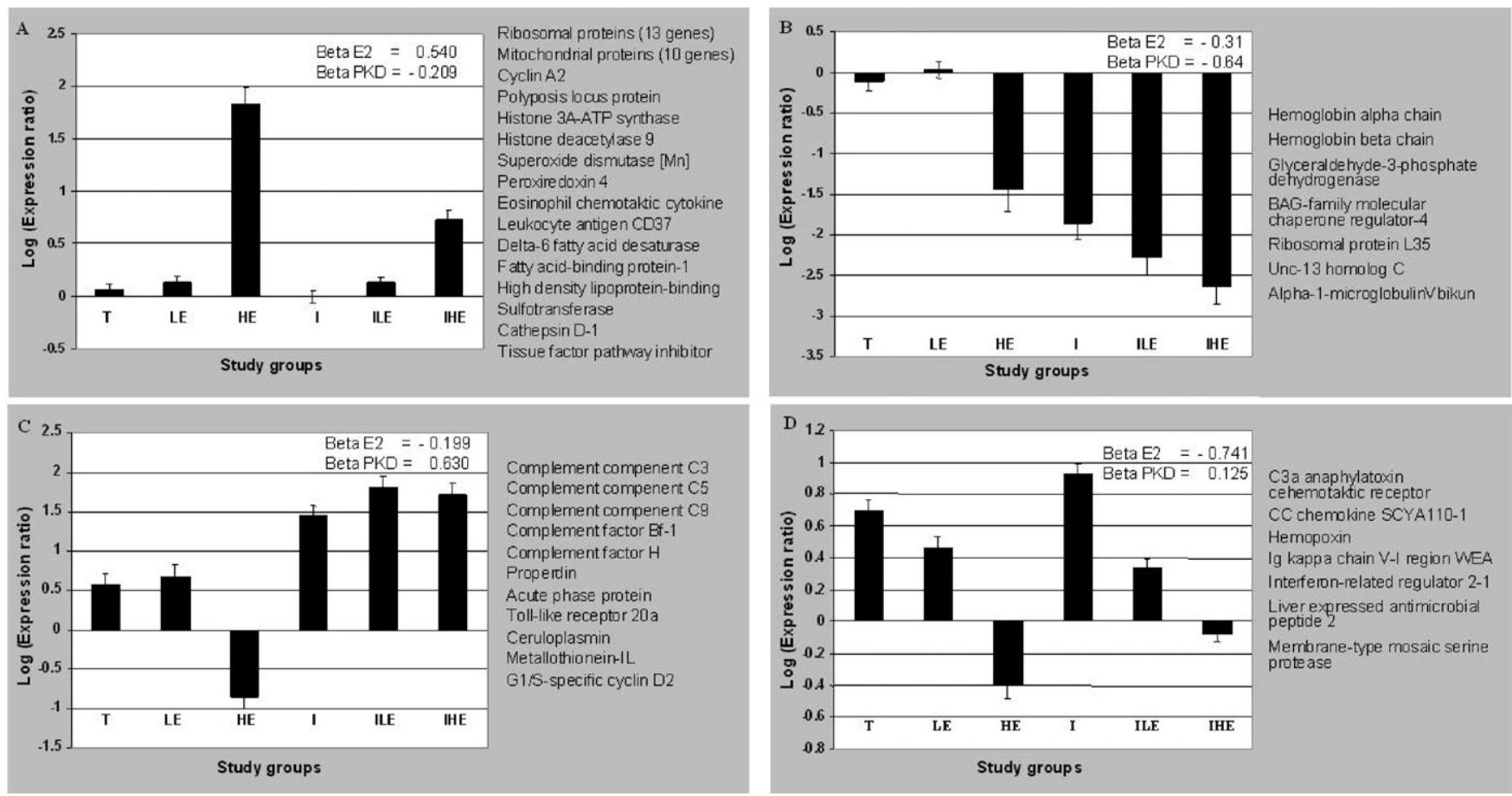

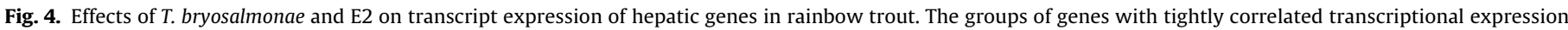

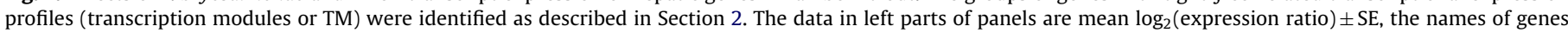

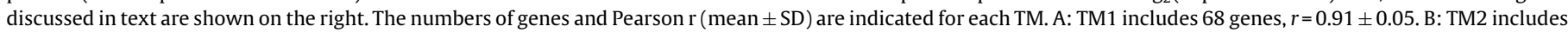
21 genes, $r=0.88 \pm 0.08$. C: TM3 includes 35 genes, $r=0.88 \pm 0.07$. D: TM4 includes 34 genes, $r=0.89 \pm 0.05$.

and Olsson, 2000). Presence of G1/S-specific cyclin D2 and growth factors in TM3 may suggest tissue repair processes in the infected fish.

\section{Discussion}

This study examined whether exposure to a combination of two environmental agents alters the reaction of rainbow trout in comparison to the single agent at the molecular level, and if this interaction relates to effects observed at the organism level. As experimental stressors we used the myxozoan parasite, $T$. bryosalmonae, which is the etiological agent of PKD, and E2 as a prototypic estrogen-active compound. Both stressors, the parasite and estrogenic contaminants, co-exist in Swiss rivers and are discussed as factors contributing to the drastic decline of Swiss brown trout populations over the last decades (Burkhardt-Holm et al., 2005). The results from the present study which point to diverse interactions of both stressors at the molecular level, but the absence of a combination effect on fish mortality does not provide evidence that the PKD impact on Swiss trout populations is enhanced by the presence of estrogen-active contaminants, although these laboratory findings would need further evaluation under field conditions to be conclusive.

In the transcriptomic part of this study, we focused on principal response patterns rather than on individual genes or pathways, as our aim was to learn how the patterns to the joint stressor impact differ from the pattern to the individual stressors. Microarray analysis of the hepatic transcriptome revealed three major response patterns to combined stressor action: (i) Transcriptional gene expression responses to one stressor are weakened by the presence of the second stressor (TM1 and TM4). In TM1, E2 upregulates transcriptional gene expression in non-infected fish, while under parasite infection, the upregulation is reduced. In TM 4, E2 alone downregulates transcriptional expression levels of the genes, whereas $T$. bryosalmonae infection upregulates the genes transcriptionally; under combined exposure, the parasitemediated induction of transcriptional gene expression as well as E2-induced downregulation are diminished. (ii) Transcriptional gene expression responses to one stressor are enhanced by the presence of the second stressor. This is the case with TM2, where genes that were transcriptionally downregulated both by E2 alone and by the parasite alone, showed an even stronger downregulation under joint exposure. (iii)Transcriptional gene expression responses at joint treatment are dominated by one of the two stressors. This is the case with TM3, where E2 alone decreases transcriptional expression of the genes, parasite infection alone increases transcriptional gene expression, and fishes exposed to both stressors exhibit transcript expression levels comparable to fishes exposed to the parasite only. The demonstration of such principal response patterns of transcriptional gene expression highlights the value of - omic approaches in studying and classifying stressor interactions.

Stressor combination effects as described above might be described in terms of antagonism, synergism or additivity. However, given the problems in aligning dose metrics of a pathogen response with dose metrics of an estrogen response, and given the fact that we have only rather few data points instead of full dose-response curves, it is difficult to interpret the results of this study under these terms. Difficulties to evaluate additive, synergistic or antagonistic effects from gene array data were also pointed out by Vinuelea et al. (2011). Therefore, we avoid the use of these terms for describing stressor interactions observed in the present study.

Genes of TM3 appeared to show no combination effect but to be exclusively responsive to parasite infection, irrespective of the simultaneous presence of E2. TM 3 contains mainly genes of the innate immune system which has a primary function in combating invading pathogens, and, therefore, genes of this system may give priority to the pathogen signal. It is tempting to speculate that the prevailing effect of the pathogenic over the estrogenic 
stressor is related to their "severity" (protection against lethal challenge dominates over sublethal damage), although this may be a rather anthropomorphic view and the question would be how the organism can sense the severity. Regardless of the responsible mechanism, TM3 points to an obvious ability of the organism for priority setting in a mixed exposure situation. This may bear implications for the risk assessment of multiple stressors, and highlights the urgent need to improve our understanding of organism's responses to combinations of chemical, physical and biological stressors.

The genes contained in TM1 encode proteins with roles in cell proliferation and DNA replication, energy metabolism, protein synthesis and secretion, lipid metabolism and responses to oxidative stress. These cellular pathways and functions are known to be estrogen-sensitive, both in mammals (e.g., Moggs, 2005) and fish (e.g., Hoffmann et al., 2006; Williams et al., 2007). In contrast to TM1, E2 alone had a transcriptional downregulating effect on genes of TM3 and TM4. As both TMs contain many immune genes, this observation points to a possible immunosuppressive activity of $\mathrm{E} 2$ in rainbow trout. Immunomodulating actions of estrogens are well documented for mammals (e.g., Martin, 2000; Straub, 2007) and increasingly also for teleost fish (e.g., Thilagam et al., 2009; Milla et al., 2011; Wenger et al., 2011). A potentially immunomodulatory role of estrogens in fish is corroborated by recent findings that estrogen receptors are expressed in piscine immune cells (Casanova-Nakayama et al., 2011). From ecoimmunological research, the existence of resource competition and trade-offs between immune functions and steroid-regulated reproductive functions is well documented (French et al., 2009), and the transcriptomic changes observed in the present study may provide initial insight into the molecular processes and mechanisms underlying such physiological trade-offs.

Transcriptional downregulation of immune genes by E2, both when administered alone (TM3) or in combination with the parasite (TM4), leads to the question if this can be translated into altered disease manifestation and T. bryosalmonae-induced mortality of trout. This was not the case in the present study, neither with respect to parasite levels in the fish host (Fig. 2) nor with respect to mortality (Fig. 1). This finding is in contrast to other studies which reported increased susceptibility of fish to immunogenic agents in the presence of estrogen-active compounds (Cabas et al., 2011; Wenger et al., 2011). To understand the absence of an E2 effect on pathogen-induced mortality in the present study, two factors need to be considered. The first factor is the hierarchy of gene responsiveness observed at the transcriptome level: although a number of immune genes was transcriptionally downregulated by E2 in the presence of parasite infection (TM4), many other immune genes (those in TM3) showed full transcriptional activation in the presence of parasite infection, up to the level as observed in the "infection only" group (genes of TM3). This implicates that under combined E2/parasite exposure, the fish organism was able to activate at least part of its immune defense, despite some immunosuppressive activities of E2, and this hierarchy of gene regulation may have translated into the absence of increased parasite susceptibility at the organism level. Also, it must not be overlooked that activation of immune responses can also have negative impacts on the host (e.g., Skugor et al., 2009), and thus, the assumption that an E2-mediated transcriptional downregulation of immune genes implicates increased pathogen susceptibility may be oversimplified. A second factor that might explain why trout exposed to both the parasite and E2 did not show increased mortalities and parasite loads is the fact that the pathogen alone resulted already in $90 \%$ cumulative mortality. Thus, there was little room left for a further increase. Wenger et al. (2011), when studying the combined impact of E2 and a bacterial pathogen on rainbow trout, used bacterial concentrations that per se caused low or moderate cumulative mortalities, and under these conditions obtained significantly increased cumulative mortalities for the E2/pathogen combinations, what was paralleled by a significantly suppressed immune response to the bacterial infection.

In conclusion, this study analyzed transcriptional responses to the joint impact of a chemical and biological stressor, and the relation of the molecular changes to organism-level responses. The findings demonstrate the existence of distinct molecular response patterns ("transcription modules", TM) to the joint impact of a chemical and biological agent. Importantly, many of the joint effects of the two stressors on transcriptional gene expression were not anticipated, i.e. could not be deduced from simply combining the results of the single treatments. In view of the diversity of the molecular response patterns, the question is which of them may be a main driver of the organism response to the stressor combination. In this study, particularly TM3, which was characterized by a dominance of the pathogenic over the estrogenic impact on gene transcription, appeared to be relevant for organism fitness - although this is a correlative and not a mechanistic statement. Finally, the question on the relation between the molecular and organism response has to be brought back into the ecological context in order to better understand how organisms handle multiple stressors.

\section{Acknowledgements}

The financial support of Swiss Nationalfunds (project No 4050066568) is gratefully acknowledged. We also thank U. Sattler (University Bern) for excellent technical assistance in performing real-time RT-PCR. Turku Centre for Biotechnology, Finland is acknowledged for preparation of microarrays.

\section{Appendix A. Supplementary data}

Supplementary data associated with this article can be found, in the online version, at doi:10.1016/j.aquatox.2012.02.026.

\section{References}

Altenburger, R., Greco, W.R., 2009. Extrapolation concepts for dealing with multiple contamination in environmental risk assessment. Integr. Environ. Assessm. Manage. 5, 62-68.

Arkoosh, M.R., Casillas, E., Huffman, P., Clemons, E., Evered, J., Stein, J.E., Varanasi, U. 1998. Increased susceptibility of juvenile Chinook salmon from a contaminated estuary to Vibrio anguillarum. Trans. Am. Fish. Soc. 127, 360-374.

Ashburner, M., Ball, C.A., Blake, J.A., Botstein, D., Butler, H., Cherry, J.M., Davis, A.P., Dolinski, K., Dwight, S.S., Eppig, J.T., Harries, M.A., Hill, D.P., Issel-Tarver, L., Kasarkis, A., Lewis, S., Matese, J.C., Richardson, J.E., Ringwald, M., Rubin, G.M., Sherlock, G., 2005. Gene ontology: tool for the unification of biology: the gene Ontology Consortium. Nat. Genet. 25, 25-29.

Bettge, K., Wahli, T., Segner, H., Schmidt-Posthaus, H., 2009a. Proliferative kidney disease in rainbow trout: time- and temperature-related renal pathology and parasite distribution. Dis. Aquat. Organ. 83, 67-76.

Bettge, K., Segner, H., Burki, R., Schmidt-Posthaus, H., Wahlim, T., 2009b. Proliferative kidney disease (PKD) of rainbow trout: temperature- and time-related changes of Tetracapasuloides bryosalmonae DNA in the kidney. Parasitology 136, 615-625.

Braunbeck,.T., Segner, H., 1992. Preexposure temperature acclimation and diet as modifying factors for the tolerance of golden ide (Leuciscus idus melanotus) to short-term exposure to 4-chloroaniline. Ecotoxicol. Environ. Saf. 24, 72-94.

Burkhardt-Holm, P., Giger, W., Güttinger, H., Ochsenbein, U., Peter, A., Scheurer, K. Segner, H., Staub, E., Suter, M.J.F., 2005. Where have all the fish gone ? Environ. I Sci. Technol. 39, 441A-447A.

Burki, R., Vermeirssen, E.L.M., Körner, O., Joris, C., Burkhardt-Holm, P., Segner, H. 2006. Assessment of estrogenic exposure in brown trout (Salmo trutta) in a Swiss midland river Integrated analysis of passive samplers, wild and caged fish, and vitellogenin mRNA and protein. Environ. Toxicol. Chem. 25, 2077-2086.

Cabas, I., Liarte, S., Garcia-Alcazar, A., Meseguer, J., Mulero, V., Garcia-Ayala, A. 2011. $17 \alpha$-Ethynylestradiol alters the immune response of the teleost gilthead seabream (Sparus aurata L.) both in vivo and in vitro. Dev. Comp. Immunol. 36, 547-556.

Callahan, M.A., Sexton, K., 2007. If cumulative risk assessment is the answer, what is the question? Environ. Health Perspect. 115, 799-806. 
Casanova-Nakayama, A., Wenger, M., Burki, R., Eppler, E., Krasnov, A., Segner, H., 2011. Endocrine disrupting compounds: can they target the immune system of fish? Mar. Pollut. Bull. 63, 412-416.

Couillard, M., Courtenay, S.C., Macdonald, R.W., Palace, V.P., 2008a. Chemical-environment interactions affecting the risk of impacts on aquatic organisms: a review with a Canadian perspective - interactions affecting exposure. Can. J. Fish. Aquat. Sci. 16, 1-7.

Couillard, M., Courtenay, S.C., Macdonald, R.W., 2008b. Chemical-environment interactions affecting the risk of impacts on aquatic organisms: a review with a Canadian perspective - interactions affecting vulnerability. Can. J. Fish. Aquat. Sci. $16,19-44$.

Coors, A., De Meester, L., 2008. Synergistic, antagonistic and additive effects of multiple stressors: predation threat, parasitism, and pesticide exposure in Daphnia magna. J. Appl. Ecol. 45, 1820-1828.

Crain, C.M., Kroeker, K., Halpern, B.S., 2008. Interactive and cumulative effects of multiple stressors in marine systems. Ecol. Lett. 11, 1304-1315.

D’Silva, J., Mulcahy, M.F., Kinkelin, P., 1984. Experimental transmission of proliferative kidney disease in rainbow trout, Salmo gairdneri Richardson. J. Fish Dis. 7, 235-239.

Felty, Q., 2006. Estrogen-induced DNA synthesis in vascular endothelial cells is mediated by ROS signaling. BMC Cardiovasc. Disord. 6, 16.

Folt, C.L., Chen, C.Y., Moore, M.V., Burnaford, J., 1999. Synergism and antagonism among multiple stressors. Limnol. Oceanogr. 44, 864-877.

French, S.S., Moore, M.C., Demas, G.E., 2009. Ecological immunology: the organism in context. Integr. Comp. Biol. 49, 246-253.

Goetz, C.W., Stamm, C., Fenner, K., Singer, H., Schärer, M., Hollender, J., 2010. Targeting aquatic microcontaminants fro monitoring: exposure categorization and application tot he Swiss situation. Environ. Sci. Poll. Res. 17, 341-354.

Guerrero, R.D., 1975. Use of androgens for the production of all-male Tilapia aurea (Steindachner). Trans. Am. Fish. Soc. 104, 342-348.

Hedrick, R.P., MacConnel, E., Kinkelin, P., 1993. Proliferative kidney disease of salmonid fish. Annual Rev. of Fish Diseases, vol. III. Pergamon Press, New York, pp. $277-290$

Heugens, E.H.W., Hendriks, A.J., Dekker, T., Van Straalen, N.M., Admiraal, W., 2001. A review of the effects of multiple stressors on aquatic organism and analysis of uncertainty factors for use in risk assessment. Crit. Rev. Toxicol. 31, 247-284.

Hoffmann, J.L., Torontali, S.P., Thomason, R.G., Lee, D.M., Brill, J.L., Price, B.B., Carr, G.J., Versteeg, D.J., 2006. Hepatic gene expression profiling using genechips in zebrafish exposed to $17 \alpha$-ethynylestradiol. Aquat. Toxicol. 79, 233-246.

Jayachandran, M., Sanzo, A., Owen, W.G., Miller, V.M., 2005. Estrogenic regulation of tissue factor and tissue factor pathway inhibitor in platelets. Am. J. Physiol. Heart Circul. Physiol. 289, 1908-1916.

Jokela, J., Taskinen, J., Mutikainen, P., Kopp, K., 2005. Virulence of parasites in hosts under environmental stress: experiments with anoxia and starvation. Oikos 108, 156-164.

Kiesecker, J.M., 2002. Synergism between trematode infection and pesticide exposure: a link to amphibian limb deformities in nature? Proc. Natl. Acad. Sci. U.S.A. 99, 9900-9904.

Kiesecker, J.M., Blaustein, A.R., Belden, L.K., 2001. Complex causes of amphibian population declines. Nature 410, 681-684.

Kling, P.G., Olsson, P.-E., 2000. Involvement of differential metallothionein expression in free radical sensitivity of RTG-2 and CHSE-214 cells. Free Radic. Biol. Med. 28, 1628-1637.

Koskinen, H., Pehkonen, P., Vehniäinen, E., Krasnov, A., Rexroad, C., Afanasyev, S. Mölsä, H., Oikari, A., 2004. Response of rainbow trout transcriptome to mode chemical contaminants. Biochem. Biophys. Res. Commun. 320, 745-753.

Krasnov, A., Koskinen, H., Rexroad, C., Afanasyev, S., Mölsä, H., Oikari, A., 2005. Transcriptome responses to carbon tetrachloride and pyrene in the kidney and liver of juvenile rainbow trout (Oncorhynchus mykiss). Aquat. Toxicol. 74, 70-81.

Krasnov, A., Afanasyev, S., Oikari, A., 2007. Hepatic responses of gene expression in juvenile brown trout (Salmo trutta lacustris) exposed to three model contaminants applied singly and in combination. Environ. Toxicol. Chem. 26, $100-109$.

Landis, W.G., Duncan, P., Hayes, E., Markiewicz, A.J., Thomas, J.F., 2004. A regional retrospective assessment of the potential stressors causing the decline of the Cherry Point Pacific Herring run. Human Ecol. Risk Assess. 3, 287-297.

MacKenzie, S., Iliev, D., Liarte, C., Koskinen, H., Planas, J., Goetz, F.W., Mölsä, H., Krasnov, A., Tort, L., 2006. Transcriptional analysis of LPS-stimulated activation of trout (O. mykiss) monocyte/macrophage cells in primary culture treated with cortisol. Mol. Immunol. 43, 1340-1348.
Martin, J.T., 2000. Sex dimorphism in immune function: the role of prenatal exposure to androgens and estrogens. Eur. J. Pharmacol. 405, 251-261.

Milla, S., Depiereux, S., Kestemont, P., 2011. The effects of estrogenic and androgenic endocrine disruptors on the immune system of fish: a review. Ecotoxicology 20 305-319.

Moggs, J.G., 2005. Molecular responses to xenoestrogens: mechanistic insights form toxicogenomics. Toxicology 213, 177-193.

Morley, N.J., 2010. Interactive effects of infectious diseases and pollution in aquatic mollusks. Aquat. Toxicol. 96, 27-36.

Nakamura, K., Yonezawa, S., Yoshizaki, N., 1996. Vitellogenesis-related ovary cathepsin D from Xenopus laevis: purification and properties in comparison with liver cathepsin D. Comp. Biochem. Physiol. 113B, 835-840.

Rice, C.D., 2001. Fish immunotoxicology: understanding mechanisms of action. In: Schlenk, D., Benson, W.H. (Eds.), Target Organ Toxicity in Marine and Freshwater Teleosts, vol. 2. Taylor \& Francis, London, pp. 96-138.

Rohr, J.R., Schotthoegr, A.M., Raffel, T.R., Carrick, H.J., Halstead, N., Hoverman, J.T. Johnson, V.M., Lieske, C., Piwoni, M.D., Schoff, P.K., Beasley, V.R., 2008. Agrochemicals increase trematode infections in declining amphibian species. Nature $455,1235$.

Segner, H., 1987. Response of fed and starved roach, Rutilus rutilus, to sublethal copper contamination. J. Fish Biol. 30, 423-438.

Segner, H., 2007. Ecotoxicology - how to assess the impact of toxicants in a multifactorial environment? In: Mothersill, C., Mosse, I., Seymour, C. (Eds.), Multiple Stressors: A Challenge for the Future. NATO Advanced Workshop. Environmenta Security. Springer, Heidelberg/New York, pp. 39-56.

Segner, H., 2011a. Moving beyond a descriptive aquatic toxicology: the value of biological process and trait information. Aquat. Toxicol. 105S, 50-55.

Segner, H., 2011b. Reproductive and developmental toxicity in fishes. In: Gupta R.C. (Ed.), Reproductive and Developmental Toxicology. Elsevier, Amsterdam, pp. $1145-1166$

Sheras, N.T., Ross, P.M., 2010. Toxic cascades: multiple anthropogenic stressors have complex and unanticipated interactive effects on temperate reefs. Ecol. Lett. 13 1149-1159.

Skugor, S., Jørgensen, S.M., Gjerde, B., Krasnov, A., 2009. Hepatic gene expression profiling reveals protective responses in Atlantic salmon vaccinated against furunculosis. BMC Genomics 10, 503

Song, J.Y., Nakayama, K., Murakami, Y., Kitamura, S.I., 2011. Heavy oil exposure induces high mortalities in virus carrier Japanes flounder (Paralichthys oliveaceus). Mar. Pollut. Bull. 63, 362-365.

Springman, K.R., Kurath, G., Anderson, J.J., Emlen, J.M., 2005. Contaminants as viral cofactors: assessing indirect population effects. Aquat. Toxicol. 71, 13-23.

Straub, R.H., 2007. The complex role of estrogens in inflammation. Endocr. Rev. 28, $521-574$

Sutherland, R.L., Prall, O.W.J., Watts, C.K.W., Musgrove, E.A., 1998. Estrogen and progestin regulation of cell cycle progression. J. Mammary Gland Biol. Neoplasia 1 63-72.

Thilagam, H., Gopalokrishnan, S., Bo, J., Wang, K.J., 2009. Effect of 17ß-estradiol on the immunocompetence of Japanese sea bass (Lateolabrax japonicus). Environ. Toxicol. Chem. 28, 1722-1731.

Vermeirssen, E.L.M., Burki, R., Joris, C., Peter, A., Segner, H., Suter, M.J.-F., BurkhardtHolm, P., 2005. Characterisation of the estrogenicity of Swiss midland rivers using a recombinant yeast bioassay and plasma vitellogenin concentrations in feral male brown trout. Environ. Toxicol. Chem. 24, 2226-2233.

Vinuelea, A., Snoek, L.B., Riksen, J.A.G., Kammenga, J.E., 2011. Gene expression modifications by temperature-toxicvant interactions in Chaneorhabditis elegans. PLoS ONE 6, e24676.

Wahli, T., Bernet, D., Steiner, P.A., Schmidt-Posthaus, H., 2007. Geographic distribution of Tetracapsuloides bryosalmonae infected fish in Swiss rivers: an update. Aquat. Sci. 69, 3-10.

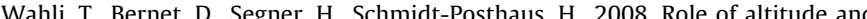
water temperature as regulating factors for the geographical distribution of Tetracapsuloides bryosalmonae-infected fishes in Switzerland. J. Fish Biol. 73 2184-2197.

Wenger, M., Sattler, U., Goldschmidt-Clermont, E., Segner, H., 2011.17Beta-estradio affects complement components and survival of rainbow trout (Oncorhynchus mykiss) challenged by bacterial (Yersinia ruckeri) infection. Fish Shellfish Immunol. 31, 90-97.

Williams, T.D., Diab, A.M., George, S.G., Sabine, V., Chipman, J.K., 2007. Gene expression of European flounder (Platichthys flesus) to 17- $\beta$ estradiol. Toxicol. Lett. 168 $236-248$ 